Research Journal of Applied Sciences 5 (6): 412-416, 2010

ISSN: $1815-932 \mathrm{X}$

(C) Medwell Journals, 2010

\title{
Incidence of Flat Foot and Anthropometric Comparison Between Flat and Normal Foot of the Yoruba Ehtnic Group of Nigeria
}

\author{
M.B.T. Umar and Adeyemi Paul \\ Department of Anatomy, University of Jos, Jos, Nigeria
}

\begin{abstract}
The deformity of flat foot (Pes planus) is a serious health problem causing gait and postural defects in all age groups. The use of anthropometric measurement has found a very salient role in the analysis of the difference that exist in the anthropometric measurement taken from individuals with flat and those with normal foot. The aim of this research work was to determine the incidence of flat foot amongst school aged children and to also determine foot anthropometry (comparison between flat and normal foot) with respect to age and gender amongst Yoruba ethnic group in Nigeria. A total of 200 students comprising of 100 males and 100 females of Yoruba origin aged 9-14 years were investigated. The following parameters were measured: Navicular Height $(\mathrm{NH})$, Medial Malleolar Height (MMH), Lateral Malleolar Height (LMH), Foot Length (FL) and Transverse Arch Length (TAL) with the aid of a ruler, marker pen and measuring tape. Mean and standard deviation of the measured parameters and other variables were determined by descriptive statistic report and t-test while their level of significance were determined using ANOVA Post Hoc Tests and independent sample $\mathrm{t}$-test at $(\mathrm{p}<0.05)$. A total of 25 individuals had flat foot comprising of 13 males and 12 females. The overall incidence of flat foot was $25 \%$ with incidence of $13 \%$ among lies and $12 \%$ among females. Following independent sample t-test analysis of the data, significant differences were found for all the measured parameters except Foot Length (FL) when children with normal foot were compared with those with flat foot. This study showed flat foot has high incidence among school aged children in Yoruba lie group with males having higher percentage incidence than females. It also showed that incidence of flat foot decreased with age all the measured anthropometric foot parameters showed male preponderance over females for normal foot type and also for flat foot except the Medial Malleolar Height (MMH) which was higher in than males. In conclusion flat footedness is one of the most prevalent foot abnormalities among the Yoruba ethnic group of Nigeria which decreases with age and has male preponderance.
\end{abstract}

Key words: Flat foot, normal foot, anthrompometric, abnormalities, preponderance, Nigeria

\section{INTRODUCTION}

In addition to the 26 bones of the foot and ankle, it also contain 23 joints, $>100$ muscles, tendons, ligaments and a net work of blood vessels, nerves, skin and soft tissues. Flatfeet describes a condition in which the longitudinal (lengthwise) and/or Medial (crosswise) arches of the foot are dropped down or flat. The entire bottom of the barefoot is in contact with the floor or ground surface during standing, walking and other weight bearing activities. The flat appearance of the foot before age 3 is normal and results partly from the thick subcutaneous fat-pad in the sole which masks the developing arch and partly because the arch has not yet fully developed.

A preponderance of flat foot was observed among 8 year olds in Taiwanese children. Multivariate analyses indicated that 8 and 9 year olds were 1.52 and
0.72 times more likely to have flat foot than 7 year olds. Males were twice as likely to have flat foot as females. The results of the study indicate that the prevalence of flexible flat foot is highest among males who are obese and over weight particularly in the age range of 7-8 years (Chang et al., 2010).

Prevalence of flat foot in healthy Turkish male adolescents was also investigated. Result shows that incidences of flat foot and high arch were $4.1 \%(\mathrm{n}=21)$ and $1.2 \%(\mathrm{n}=6)$, respectively. There were no significant differences between sex and age groups with respect to the frequency of both deformities ( $p>0.05$ ). No association were found between the presence of flat foot or high arch and body weight, body height, BMI, foot length, metatarsal width and shoe size ( $p>0.05)$. Only heel width showed a significant association with the presence of flat foot $(p=0.027)$. Conclusively, these finding suggest that the presence of high arch is not related to body

Corresponding Author: M.B.T. Umar, Department of Anatomy, University of Jos, Jos, Nigeria 
composition and foot dimensions while flat foot is associated only with heel width (Atamturk, 2009). Rigid and resistant flat foot can cause severe disability. Therefore, the possibility of flat foot should be kept in mind in symptomatic male adolescents (Cilli et al., 2009).

The prevalence of Pes planus was determined among the people of Akwa Ibom state of southern Nigeria. The overall prevalence of Pes planus was $13.4 \%$ with a prevalence of $5.8 \%$ among males and $7.6 \%$ among females Bilateral flat foot was commoner among females (6.2\%) them males $(5.0 \%)$. Unilateral flat foot was also commoner among females $(1.4 \%)$ compared to males $(0.8 \%)$. Prevalence of Pes planus was higher among females than males in Akwa Ibom state of Nigeria (Eluwa et al., 2009).

\section{MATERIALS AND METHODS}

Origin of sample and inclusion criteria: The study was carried out in three different Yoruba communities:

- Lagos (Western College, Yaba), Lagos state

- Osogbo (The lady and St. Francis Catholic College), Osun state

- Ilorin (Kwara State Polytechnic Secondary School), Kwara state

The subjects, whose ages ranged between 9 and 14 were selected randomly from the general population of junior secondary school students i.e., JSS 1-JSS 3 in the three Yoruba communities. For a subject to be accredited into the study population, the parents and grand parents had to be of Yoruba ethnic group origin. A total of 200 school aged children (100 boys and 100 girls) were included in this study.

Sampling and sampling technique: In this research project, the sampling technique used is the cross sectional mode due to the nature of the population and the age range so used.

Research materials/instruments: In this study a ruler, a marker pen and a measuring tape were basically used:

Ruler: This was used for the measurements of the navicular height, medial malleaolar height and the lateral malleolar height from the ground to their various landmarks.

A marker pen: This was used to mark out the various bony landmarks before the measurements were taken.

Measuring tape: This was used to measure the foot length and the transverse arch.
Method of data collection: All measured foot were parameters were taken from the left side of the body (mainly for convenience). The following parameters were measured Navicular height, transverse arch, foot length, medial malleolar height and lateral malleolar height:

- Lateral Malleolar Height (LMH) was measured from the floor to the most anterior inferior portion of the lateral malleolus

- Medial Malleolar Height (MMH) was measured from the floor to the most anterior inferior portion of the medial malleolus

- Foot Length (FL) was measured from the most posterior position of the calcaneus to the end of the longest toe

- Navicular Height $(\mathrm{NH})$ was measured from the floor to the most anterior inferior portion of the navicular bone

- Transverse Arch Length (TAL) was measured from the base of the last metatarsal bone ( 5 th toe) to that of the first toe that is to base of the last metatarsal of the last metatarsal (1st toe)

These parameters would be compared in individuals with the flat foot deformity and those with normal feet. Measurements of these parameters were done using visual assessment and bony landmarks. But in the case of the medial longitudinal arch, visual assessment tend to give results far from being accurate. Therefore to measure the medial longitudinal arch more accurately, researchers in this field divide the navicular height by the foot length.

As observed in the course of this study, measurement of foot length can be skewed by foot deformities such as hallux valgus and claw toes. Therefore, individuals with such deformities as stated above did not have their feet measured. On the other hand individuals with the flat feet deformity had their feet carefully measured for the comparison made in the foot. The results obtained from the various foot anthropometric parameters measured and other variables such as age and gender were analysed using statistical packages SPSS.

\section{RESULTS}

From the study, we have these results:

- $\quad$ Total number of subject $=200$

- Total number of female subjects $=100$

- $\quad$ Total number of male subjects $=100$

- Number of females with flat foot deformity $=12$

- Number of males with flat foot deformity $=13$

- Total number of individual with flat foot $=25$

- Percentage incidence of flat foot among total population $=12.5 \%$ 
- Percentage incidence of male subjects with flat foot deformity among the total subjects with flat feet $(\mathrm{n}=200)$ was $52 \%$

- Percentage incidence of male subjects with flat foot deformity among total male population $(\mathrm{n}=100)$ was $13 \%$

- Percentage incidence of female subjects with flat foot deformity among the total subjects with flat feet $(\mathrm{n}=25)$ was $48 \%$

- Percentage incidence of female subjects with flat foot deformity among total population $\mathrm{n}=100$ was $12 \%$

- Over all percentage incidence of students with flat feet was $25 \%$

\section{DISCUSSION}

In this present study, the incidence of Pes planus (flat foot) was determined among a total population of 200 school aged students (100 males and 100 females) aged between 9-14 years who were Yoruba (parents and grand parents were Yoruba) and also resident within Yoruba communities. The participants were analysed in three age brackets namely 9-10, 11-12 and 13-14 years, respectively. The over all incidence percentage of flat foot among the total population studied was as high as $25 \%$ with $13 \%$ in males and $12 \%$ in females.

Many studies have been carried out to determine the prevalence of flat foot with respect to different age group and gender in Nigeria and other parts of the world. Didia et al. (1987) investigated the prevalence of flat foot among school children in Port Harcourt, Nigeria. In that study, the prevalence of unilateral Pes plauns was found to be $2.22 \%$. Further investigation by Didia and Asomugha (2004) reported an incidence of 3.5\% among athletes in Port Harcourt. Elsewhere in Africa, in Kenya to be Igbigbi et al. (2005) reported a prevalence of 430 per 1000 population. In Kenyans, the highest ever documented and twice as high as that in Tanzanians (230 per 1,000 population).

The result of this current study showed a high percentage incidence of flat foot among the school aged students in Yoruba ethnic group when compared with the results of investigated cases mentioned above and the result is also in agreement with the report given by Yucesan et al. (1993) where flat foot was found to the most prevalent congenital abnormalities in children $(2.28 / 1,000)$ among 19750 Turkish school children aged 6-15 years.

Considering the percentage incidence for sexual dimorphism, the incidence percentages of flat foot in a total population of 1,222 among Taiwanese School aged children were $67 \%$ for males and $49 \%$ for females (Chang et al., 2010).
Another result from Taiwan gave a prevalence of $35 \%$ in boys and $20 \%$ in girls for a total of 1,024 school children (549 boys and 475 girls) aged 5-13 years. Chen et al. (2009). In both cases considered above, males have higher percentage incidence than females which is in agreement with the result obtained in this current study. Although, the two cases considered above showed that males had a significantly higher percentage incidence than females when compared with the resent study, this could be as a result of larger population samples of 1,222 and 1024 in those two cases considered compared with limited sample in this current study.

However, when the result of this present study was compared with the result of a research work by Eluwa et al. (2009) on the prevalence of flat foot among the Southern Nigeria (Akwa Ibom state), females had higher prevalence percentage than males. One explanation for this could be difference in age groups considered in both cases. While the Akwa Ibom study considered age group 20-30 years, this current study dwelled on school aged students between the ages of 9-14 years. This higher prevalence among females may also be due to the fact that adult females tend to have small bones and less bulky muscles. Since both factors help in the maintenance of the arches of the foot (Hicks, 1955). Out of the five foot anthropometric parameters that were measured only foot length showed no significant difference. Others were significantly higher in normal foot than flat foot (Table 1).

The mean navicular height which was used to classify a foot into either flat or normal in this study it was $5.16 \mathrm{~cm}$. This value is slightly higher than the reported value of $3.8-40 \mathrm{~cm}$ in normal weight subject (Morrison et al., 2007). This difference could be ascribed to certain reasons such as environmental, dietary or/and genetic factors.

The occurrence of flat foot decreases with increase in age as shown in Table 2. This result is in concordance with the result in the literature reported by Chen et al. (2009) and Pfeiffer et al. (2006). They reported that prevalence of flat foot decreases significant with age.

Table 1: Comparison of descriptive statistics of foot parameters by foot types

\begin{tabular}{llclcc}
\hline & \multicolumn{2}{l}{ Flat foot } & \multicolumn{2}{l}{ Normal foot } & \\
Variables & N & Mean \pm SD $(\mathrm{cm})$ & \multicolumn{1}{l}{ N } & Mean \pm SD $(\mathrm{cm})$ & p-value \\
\hline NH & 25 & $4.04 \pm 0.168$ & 175 & $5.16 \pm 0.518$ & $0.000^{*}$ \\
MMH & 25 & $5.85 \pm 0.403$ & 175 & $6.17 \pm 0.680$ & $0.000^{*}$ \\
FL & 25 & $23.30 \pm 1.627$ & 175 & $23.68 \pm 1.386$ & 0.215 \\
LMH & 25 & $5.30 \pm 0.621$ & 175 & $6.02 \pm 0.701$ & $0.000^{*}$ \\
TAL & 25 & $12.87 \pm 0.857$ & 175 & $13.41 \pm 0.938$ & $0.007^{*}$
\end{tabular}

$\mathrm{N}=$ Number of cases, $\mathrm{SD}=$ Standard Deviation; The mean values of normal foot parameters were generally slightly higher than their corresponding flat foot parameters and they were significantly higher at $p$-values indicated except for foot length which showed no significant difference 
Table 2: Comparision of descriptive statistics of parameters by foot types with respect to age groups (9-10yrs)

\begin{tabular}{|c|c|c|c|c|c|c|}
\hline \multirow[b]{2}{*}{ Variables } & \multicolumn{2}{|c|}{ Flat foot } & & \multicolumn{2}{|c|}{ Normal foot } & \multirow[b]{2}{*}{$\mathrm{p}$-value } \\
\hline & $\mathrm{N}$ & Mean \pm SD (cm) & $\mathrm{p}$-value & $\mathrm{N}$ & Mean \pm SD $(\mathrm{cm})$ & \\
\hline \multicolumn{7}{|c|}{ Age group (9-10 years)* } \\
\hline $\mathrm{NH}$ & 15 & $4.02 \pm$ & 0.644 & 75 & 14 & 0.1 \\
\hline IMI & 15 & 5 & .025 & 75 & & .828 \\
\hline $\mathrm{L}$ & 15 & 23 & 0.683 & 75 & & 0.996 \\
\hline $\mathrm{MH}$ & 15 & & & 75 & & 0.950 \\
\hline TAL & 15 & 12.8 & 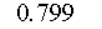 & 75 & & 0.129 \\
\hline \multicolumn{7}{|c|}{ Age group (11-12 years) ${ }^{* * *}$} \\
\hline $\mathrm{H}$ & 7 & & & 57 & & 0.149 \\
\hline $\mathrm{MH}$ & 7 & 60 & 0.623 & 57 & & 0.828 \\
\hline L L & 7 & 22 & 0683 & 57 & & 0.996 \\
\hline LMH & 7 & & & 57 & & 0.950 \\
\hline $\mathrm{AL}$ & 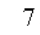 & $12.74 \pm 0.8$ & 0.7 & 57 & 35 & 0.129 \\
\hline \multicolumn{7}{|c|}{ Age group (13-14 years) $)^{\text {*k*k:k }}$} \\
\hline 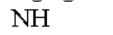 & 0 & & & & & 0.386 \\
\hline Fe & 3 & & & 43 & & 0.159 \\
\hline${ }^{T L}$ & 3 & $25.00 \pm 2.500$ & 0.076 & 43 & $23.46 \pm 1.492$ & 0.278 \\
\hline $\mathrm{MH}$ & 3 & $5.33 \pm 0.306$ & 0.949 & 43 & $6.21 \pm 0.699$ & 0.057 \\
\hline
\end{tabular}

*For age group 9-10 years means value of normal foot parameters were higher than those of flat foot but there were no significant difference between them. **For age group 11-12 years, the mean values of normal foot were higher than those of flat foot but no significant different even when compared using multiple comparison LSD; ****; For age group 13-14 years, the mean values of normal foot were higher than those of flat except for foot length where the reverse was the case. Following multiple comparison by LSD, no significance difference observed

Table 3: T-test for gender difference (flat foot)

\begin{tabular}{|c|c|c|c|c|c|}
\hline \multirow[b]{2}{*}{ Variables } & \multicolumn{2}{|c|}{ Male } & \multicolumn{2}{|c|}{ Female } & \multirow[b]{2}{*}{$p$-value } \\
\hline & $\mathrm{N}$ & Mean \pm SD $(\mathrm{cm})$ & $\mathrm{N}$ & Mean \pm SD $(\mathrm{cm})$ & \\
\hline $\mathrm{NH}$ & 13 & $4.09 \pm 0.150$ & 12 & $3.98 \pm 0.175$ & 0.117 \\
\hline $\mathrm{MMH}$ & 13 & $5.83 \pm 0.390$ & 12 & $5.88 \pm 0.433$ & 0.791 \\
\hline FL & 13 & 25.5 & 12 & $23.02 \pm 1.003$ & 0.408 \\
\hline LMH & 13 & $5.55 \pm 0.704$ & 12 & $5.04 \pm 0.397$ & $0.040^{*}$ \\
\hline ГAL & 13 & $12.88 \pm 0.904$ & 12 & $12.86 \pm 0.844$ & 0.958 \\
\hline
\end{tabular}

The mean values of flat foot parameter were slightly higher in males than their corresponding female subjects except for $\mathrm{MMH}$ which had a higher value in female than male. However, LMH showed a significant statistical mean difference between males and females at $(p<0.05)$

Table 4: T-test for gender difference (normal foot)

\begin{tabular}{llclrl}
\hline \multicolumn{5}{l}{ Males } & \multicolumn{2}{l}{ Females } & \\
Variables & $-\mathrm{N}$ & Mean \pm SD $(\mathrm{cm})$ & $\mathrm{N}$ & Mean \pm SD $(\mathrm{cm})$ & p-value \\
NH & 87 & $5.22 \pm 0.607$ & 88 & $5.09 \pm 0.401$ & 0.084 \\
MMH & 87 & $6.76 \pm 0.742$ & 88 & $6.67 \pm 0.615$ & 0.424 \\
FL & 87 & $24.16 \pm 1.518$ & 88 & $23.20 \pm 1.050$ & $0.000^{*}$ \\
LMH & 87 & $6.08 \pm 0.726$ & 88 & $5.95 \pm 0.674$ & 0.211 \\
TAL & 87 & $13.64 \pm 1.114$ & 88 & $13.18 \pm 0.651$ & $0.001^{*}$
\end{tabular}

The mean values of normal foot parameters were higher in male than in females. Also, FL and TAl measurements demonstrated a significant statistical mean difference between males and females at $(p<0.05)$

Table 2 also showed that for all the measured foot parameters normal foot had higher values than flat foot except for foot length where the reverse was the case. Though, the differences were not significant. In Table 3, all measured parameters showed male preponderance over female except for the medial malleolar height. Following independent sample t-test analysis of the data, lateral malleolar height was found to be significantly higher in males than females at $p=0.040$. This male preponderance over females for the measured parameters is in close agreement with higher percentage incidence of flat foot in males than females as pointed out above. Out of the five anthropometric foot parameters measured for normal foot (Table 4), foot length and transverse arch length were significantly higher in males than females.

\section{CONCLUSION}

In conclusion, flat footedness can be said to be one of the most prevalent foot abnormalities among school aged children aged 9-14 years in Yoruba ethnic group of Nigeria with a percentage incidence of $25 \%$ sampled population. The results so obtained from the research work and statistical analysis carried out suggested that the incidence of flat foot among school aged children is influenced by age and gender. The incidence of flat foot decreases with age which could be due the fact that flat arches in children usually become proper arches and high arches while the child progresses through adolescence and into adulthood. The result also indicated that all the measured anthropometric foot parameters showed male preponderance over females for normal foot type and also for flat foot type except the medial malleolar height which was higher in females than males meaning that male subjects process higher tendency to develop flat foot than their female counter parts.

\section{RECOMMENDATION}

In forensic investigation, difficulties are being experienced in the stature, gender and age estimation of bodies dismembered in mass destruction. We therefore recommend formulae for estimation of the stature, gender and age of an individual through foot measurement for further studies in this ethnic Nigerian ethnic group.

\section{ACKNOWLEDGEMENT}

The researchers wish to acknowledge the immense contributions of Tafida Rabiu towards the successful collection of the data used in this reasearch.

\section{REFERENCES}

Atamturk, D., 2009. Relationship of flat foot and high arch with main anthropometric variables. Acta Orthop. Traumatol. Turc., 43: 254-259.

Chang, J.H., S.H. Wang, C.L. Kuo, H.C. Shen, Y.W. Hong and L.C. Lin, 2010. Prevalence of flexible flat foot in Taiwanese School-aged children in relation to obesity, gender and age. Eur J. Pediatrics, 169: 447-452.

Chen, J.P., M.J. Chung and M.J. Wang, 2009. Flat foot prevalence and foot dimensions of 5 to 13 year old children in Taiwan. Foot Ankle Int., 30: 326-332. 
Cilli, F., O. Pehlivan, K. Keklikcik, M. Mahirogullari and M. Kuskucu, 2009. Prevalence of flat foot in Turkish male adolescents. Eklem. Hastalik Cerrahisi, 20: 90-92.

Didia, B.C. and A.L. Asomugha, 2004. The incidence of flat foot amongst athletes in Port Harcourt. J. Exp. Clin. Anat., 3: 58-59.

Didia, B.C., E.T. Omu and A.A. Obuoforibo, 1987. The use of footprint contact index II for the classification of flat foot in a Nigerian population. Foot Ankle, 7: 285-289.

Eluwa, M.A., R.B. Omini, T. Kpela, T.B. Ekanem and A.O. Akpantah, 2009. The incidence of pes planus amongst akwa ibom state students in the university of calabar. Internet J. Forensic Sci., 3: 2-2.

Hicks, J.H., 1955. The foot as a support. Acta Anatomica, 25: $34-35$.
Igbigbi, P.S., B.C. Msamati and M.B. Sheriff, 2005. Arch index as a predictor of pes planus: A comparative study of indigenous Kenyans and Tanzanians. J. Am. Podiatr. Med. Assoc., 95: 273-276.

Morrison, S.C., B.R. Durward, G.F. Watt, D.C.S. Malcolm, 2007. Anthropometric foot structure of periputbescent children with excursive versus normal body mass. J. Am. Podiatric Med. Assoc., 5: 366-370.

Pfeiffer, M., R. Kotz, T. Ledl, G. Hauser and M. Slugn, 2006. Prevalence of flat foot in preschool-aged children. Pedicatrics, 118: 634-639.

Yucesan, S., H. Dindar, I. Olcay, H. Okur and S. Killicaslan et al., 1993. Prevalence of congenital abnormalities in Turkish school children. Eur. J. Epidemiol., 9: 373-380. 